\title{
Introducing an alternative biophysical method to analyze direct G protein regulation of voltage-dependent calcium channels
}

\author{
Norbert Weiss $^{\mathrm{a}}$ \& Michel De Waard ${ }^{\mathrm{a}^{*}}$ \\ anserm U607, Laboratoire Canaux Calciques, Fonctions et Pathologies, Université Joseph \\ Fourier, Grenoble 38054, France ; Commissariat à l’Energie Atomique, Grenoble, France ; \\ Université Joseph Fourier, Grenoble, France.
}

Number of pages in manuscript: 20 - Number of figures 6 - Number of tables 0

\section{* Corresponding author:}

Dr. Michel De Waard

Inserm U607, CEA, 17 Rue des Martyrs, Bâtiment C3, 38054 Grenoble Cedex 09, France.

Tel. (33) 438786813

Fax (33) 438785041

E-mail address: mdewaard@cea.fr 


\begin{abstract}
Direct $G$ protein inhibition of voltage-dependent calcium channels is currently indirectly assessed by the gain of current produced by depolarizing prepulse potentials (PP). Indeed, PPs produce a channel opening- and time-dependent dissociation of G proteins from the channel that is responsible for the increase in $\mathrm{Ca}^{2+}$ permeation. Parameters of $\mathrm{G}$ protein dissociation are essential to describe the characteristic landmark modifications in channel activities that underlie $G$ protein regulation. From the kinetics and opening-dependence of this dissociation, crucial biophysical parameters are extracted such as the extent and the rate of $\mathrm{G}$ protein unbinding from the channel. Unfortunately, the method used so far assumes that $G$ protein regulated channels undergo the same inactivation kinetics than control channels. Herein, we demonstrate for the first time that $G$ protein-bound channels undergo a much slower inactivation than control channels. We thus introduce a novel simple-to-use method that avoids the use of PPs and that is not affected by potential changes in channel inactivation kinetics conferred by $G$ protein binding. This method extracts $G$ protein unbinding parameters from ionic currents induced by regular depolarizing pulses by separating the ionic currents due to non-regulated channels from the ionic currents that result from a progressive departure of $G$ proteins from regulated channels.
\end{abstract}

Keywords: Calcium channel, $\mathrm{Ca}_{\mathrm{v}} 2.2$ channel, mu-opioid receptor, $\beta$-subunit, $\mathrm{G}$ protein regulation, prepulse facilitation, biophysical method. 


\section{Introduction}

Many neuronal voltage-dependent calcium channels are strongly regulated by G protein coupled receptors (GPCR) (Bean, 1989; Dunlap and Fischbach, 1981; Lipscombe et al., 1989; Marchetti et al., 1986). Direct current inhibition occurs through binding of the $G_{\beta \gamma}$ dimer of $\mathrm{G}$ proteins onto one of the three potential $\mathrm{Ca}_{\mathrm{v}} 2$.x pore-forming subunits $\left(\mathrm{Ca}_{\mathrm{v}} 2.1\right.$, $\mathrm{Ca}_{v}$ 2.2, and $\mathrm{Ca}_{v} 2.3$ ) (Bourinet et al., 1996; Roche et al., 1995). Many modifications in channel activity have been used for the identification of direct $G$ protein regulation. At the whole-cell level, these modifications include: i) current inhibition (Boland and Bean, 1993; Wu and Saggau, 1997), ii) slowing of activation kinetics (Marchetti et al., 1986), iii) current facilitation following membrane depolarization with strong prepulse application (Ikeda, 1991; Scott and Dolphin, 1990), and iv) shift in the voltage-dependence of activation towards depolarized values (Bean, 1989). The current inhibition is definitively linked to G protein association onto the channel, whereas the slowing of activation kinetics as well as the current prepulse facilitation are interpreted as due to G protein dissociation (Elmslie and Jones, 1994; Stephens et al., 1998). The interpretation of the shift of the voltage-dependence of activation is possibly less clear, but it might also be linked to the process of $\mathrm{G}$ protein dissociation during membrane depolarization (De Waard et al., 2005). Single channel recordings have shown that $G$ proteins produce an increase in the first latency to channel opening and in the occurrence of sweeps without openings (Carabelli et al., 1996; Patil et al., 1996). For N-type calcium channels, some manuscripts have reported openings in a reluctant mode (Lee and Elmslie, 2000; Colecraft et al., 2000), while others show no evidence (Carabelli et al., 1996; Patil et al., 1996). It has been concluded that the channel can recuperate a normal activity only once the $G_{\beta \gamma}$ dimer has physically dissociated from the channel. Early steps in channel openings produced during membrane depolarization represent the incentive for this dissociation (Jones and Elmslie, 1997; Patil et al., 1996). Thus, since $G_{\beta \gamma}$ dissociation from the channel is at the onset of major biophysical changes in calcium currents, studying the parameters that underlie $G_{\beta \gamma}$ dissociation appears particularly important to understand channel regulation by $\mathrm{G}$ proteins. In particular, the extent of inhibition at resting potential, the rate at which $G$ proteins unbind from the channel during membrane depolarization, as well as the extent at which this dissociation occurs require a precise quantification. Classically, the two last parameters are extracted by the use of depolarizing prepulse potentials (Roche and Treistman, 1998). However, using depolarizing prepulses also induces channel inactivation, which partly masks the net current facilitation component making it difficult to measure $G$ 
protein dissociation parameters. In order to eliminate this component of prepulse-induced inactivation and to better extract these $G$ protein dissociation parameters, the facilitated current under $G$ protein regulation is normalized to the values observed in the absence of $G$ protein regulation. This strategy of analysis assumes that calcium channels under the control of $G$ proteins inactivate to a similar extent and with the same rate than control channels. As we will show here in this study, this assumption is put into question. Also, this method assumes that $\mathrm{G}$ protein dissociation occurs only during the depolarizing prepulse application and not during the pulse test which is not supported by the experimental evidences. In this context, we propose an alternative method that is not based on these assumptions, thereby allowing a description of the critical parameters supporting $G$ protein regulation of voltagedependent calcium channels. 


\section{Materials and methods}

\subsection{Materials}

cDNAs coding for rabbit $\mathrm{Ca}_{\mathrm{v}} 2.2$ (accession number D14157), rat $\beta_{3}$ (M88751) and rat $\mu$-opioid receptor (rMOR) were used in this study. (D-Ala ${ }^{2},{\mathrm{Me}-\mathrm{Phe}^{4} \text {,glycinol }}^{5}$ )-Enkephalin (DAMGO) was purchased from Bachem (Bubendorf, Germany).

\subsection{Transient expression in Xenopus oocytes}

Stage V and VI oocytes were surgically removed from anesthetized adult female Xenopus laevis and treated for 2-3 h with $2 \mathrm{mg} / \mathrm{ml}$ collagenase type 1A (Sigma). Cytoplasmic injection of cells was performed with $46 \mathrm{nl}$ of cRNA mixture $\left(\mathrm{Ca}_{\mathrm{v}} 2.2\right.$ and rMOR cRNA at 0.3 $\mu \mathrm{g} / \mu \mathrm{l}+0.1 \mu \mathrm{g} / \mu \mathrm{l}$ of $\beta_{3} \mathrm{cRNA}$ ) in vitro transcribed using the SP6 or T7 mMessage mMachine Kit (Ambion, Cambridgeshire, UK). Cells were incubated at $19^{\circ} \mathrm{C}$ in defined nutriment oocyte medium as described (Eppig and Dumont, 1976). Surgeries on frogs were carried out in accordance with the European Communities Council Directive of 24 November 1986 (86/609/EEC). Formal approval was obtained from the animal subjects review board of Inserm. Minimal numbers of animals were used for this study.

\subsection{Electrophysiological recording}

After 2-4 days incubation, macroscopic currents were recorded at room temperature using the Digidata 1322A and GeneClamp 500B amplifier (Axon Instruments, Union City, CA) by the two-electrode voltage-clamp technique in a bathing solution containing (in $\mathrm{mM}$ ): $\mathrm{Ba}(\mathrm{OH})_{2} 40, \mathrm{NaOH} 50, \mathrm{KCl}$ 3, HEPES 10, niflumic acid 0.5, $\mathrm{pH} 7.4$ with methanesulfonic acid. Niflumic acid was used because it is one of the rare known voltage-independent blocker of calcium-activated chloride currents (Qu and Hartzell, 2001). Electrodes were filled with (in mM): KCl 140, EGTA 10 and HEPES 10 (pH 7.2) and had resistances comprised between 0.5 and $1 \mathrm{M} \Omega$. All electrophysiological acquisition and analyses were performed with the pClamp 8 software (Axon Instruments). Recordings were low-pass filtered at $2 \mathrm{kHz}$ and acquired at 10 $\mathrm{kHz}$. Leak subtraction was performed on-line by a P/4 protocol. The holding potential was -90 $\mathrm{mV}$ throughout. For prepulse facilitation experiments, a $20 \mathrm{~ms}$ interpulse to $-90 \mathrm{mV}$ was used. DAMGO was applied at a saturating concentration of $10 \mu \mathrm{M}$ by superfusion of cells at 1 $\mathrm{ml} / \mathrm{min}$. All recordings were performed within $1 \mathrm{~min}$ after DAMGO produced maximal current inhibition. We observed that this procedure greatly minimized voltage-independent G 
protein regulation that took place later, 5 to 10 min after DAMGO application (data not shown). Only the voltage-dependent component was studied by prepulse applications. The inhibition by DAMGO was fully reversible as assessed by washout experiments. Also, no run-down was observed during the time course of these experiments.

\subsection{Data analysis}

Cells lacking tonic $G$ protein inhibition with current densities less than $2 \mu \mathrm{A} / \mu \mathrm{F}$ were selected for our analyses. All data are presented as mean \pm SEM for $n$ number observations and statistical significance $(p)$ was calculated using the unpaired Student's $t$-test. 


\section{Results}

\subsection{Biophysical parameters of $G$ protein regulation extracted by the classical prepulse method}

The electrophysiological protocol used in the prepulse method is shown in Fig. 1A. Basically, kinetics and extent of recovery from G protein inhibition are determined by comparing peak current amplitudes at a test pulse before (P1) and after (P2) application of depolarizing prepulses of variable voltages and durations both in control and DAMGO conditions. Representative examples are shown for $\mathrm{Ca}_{\mathrm{v}} 2.2$ / $\beta_{3}$ channels with a 500 ms test pulse at $10 \mathrm{mV}$ and a prepulse at $70 \mathrm{mV}$ of variable duration (Fig. 1B). Notably, a significant extent of current inactivation is produced by application of $70 \mathrm{mV}$ prepulses (see current amplitude decline in control conditions). Under G protein inhibition, prepulse applications of increasing durations induce a current facilitation that progressively declines with longer depolarizing prepulses. Since depolarizing prepulses induce both current facilitation and channel inactivation, P2 currents are affected by a gain of current due to G protein dissociation from the channel and a loss of current resulting from channel inactivation. For short prepulses, the gain of current is predominant, whereas the tendency is inverted by increasing prepulse duration, at time points where $G$ protein dissociation saturates but channel inactivation increases. The control condition contains only the prepulse-induced inactivation component, whereas the DAMGO condition contains both the facilitation component and the inactivation component. The average behaviour of normalized peak currents (P2/P1) are plotted as a function of prepulse duration for both control and DAMGO conditions for a prepulse potential of $70 \mathrm{mV}$ (Fig. 1C). The inactivation component is evident in control condition, whereas it appears more lately in the DAMGO condition. In order to isolate the net facilitation component in the DAMGO condition, the evolution of P2/P1 in DAMGO condition is normalized with regard to the evolution of P2/P1 in control condition. The result of this procedure is shown in Fig. 1D. Fitting the results by a single exponential rise to max provides the following parameters: the time constant of $G$ protein dissociation $(\tau=19.6 \pm 2.6$ $\mathrm{ms}$ at $70 \mathrm{mV}, \mathrm{n}=7$ ) as well as the extent of facilitation (1.6 \pm 0.2 fold, $\mathrm{n}=7$ ). Extracting $\mathrm{G}$ protein dissociation parameters with the prepulse method implies that control and G proteininhibited channels inactivate similarly (same rate and same extent of inactivation). If this condition is not fulfilled, then the last normalization procedure is flawed by approximation. 


\subsection{Activated $G$ proteins modify the inactivation behaviour of $C a_{v} 2.2$ / $\beta_{3}$ channels}

Examining whether $G$ proteins alter channel inactivation is particularly difficult because $G$ protein-inhibited channels do not carry currents and hence the inactivation of non conducting channels is difficult to follow. Examining this matter thus requires an indirect approach. In our conditions, at a test potential of $20 \mathrm{mV}$, application of $10 \mu \mathrm{M}$ DAMGO induces different characteristic effects of direct $G$ protein inhibition as shown in the representative current traces (Fig. 2Aa). The maximal G protein inhibition of $\mathrm{Ca}_{\mathrm{v}} 2.2 / \beta_{3}$ currents by DAMGO is $61.4 \pm 2.3 \%$ (measure at peak currents, $n=7$ ) (Fig. 2Ab). Two other hallmarks of $\mathrm{G}$ protein regulation are a slowing of activation kinetics reflected by a shift in the time to peak of the current $(39.8 \pm 4.6 \mathrm{~ms}, \mathrm{n}=7)$ (Fig. 2Ac) and the slowing of inactivation kinetics (1.8 \pm 0.2 fold, $n=7)$ (Fig. 2Ad). Alterations in current kinetics are due to a population of channels that progressively recover from $G$ protein inhibition (Elmslie and Jones, 1994). This recovery is linked to channel opening following membrane depolarization (Patil et al., 1996). Hence, the shape of the current is representative of a defined proportion of channel populations, a group of control channels (with unmodified activation and inactivation kinetics) and a group of $G$ protein-inhibited channels that undergo recovery from inhibition and contributes to the slowing of current kinetics. Modifying the proportion of these two channel populations should result in a modification of the shape of this current. Faster kinetics would suggest a greater proportion of control channels, and slower kinetics would imply a greater proportion of $\mathrm{G}$ protein-inhibited channels. If $\mathrm{G}$ proteins alter the kinetics of channel inactivation, then one would expect that an inactivating conditioning pulse of variable duration should alter the proportion of channel populations during the time course of this conditioning pulse, and, therefore, the shape of the current under DAMGO (as shown in the protocol of Fig. 2B). There are three possibilities:

1- G protein-inhibited channels inactivate at the same rate as control channels: the ratio between the two populations of channels remains constant during this conditioning pulse and the shape of the current induced by the test pulse at $20 \mathrm{mV}$ remains unaltered (Fig. 2Ba).

2- G protein-inhibited channels inactivate faster than control channels: the ratio progressively becomes in favour of control channels, and the kinetics of the test pulse current is accelerated to converge towards control current (Fig. 2Bb). 
3- G protein-inhibited channels inactivate slower than control channels: the ratio becomes in favour of $G$ protein-inhibited channels, and the kinetics of the test pulse current is further slowed (Fig. 2Bc).

Fig. 2Ca illustrates representative current traces obtained at a test pulse of $20 \mathrm{mV}$ following an inactivating conditioning pulse at $-30 \mathrm{mV}$. This conditioning pulse was chosen because it produces maximal inactivation without any activation (activation threshold is at $-10 \mathrm{mV}$ for $\mathrm{Ca}_{\mathrm{v}} 2.2 / \beta_{3}$ channels). Varying the duration of this inactivating pulse, to alter the amount of inactivation of both channel populations, results in a slowing of activation and inactivation kinetics of DAMGO regulated currents. Activation and inactivation parameters were quantified by measuring, respectively, the time to peak of the currents (Fig. 2Cb) and the rate of inactivation (Fig. 2Cc) as a function of inactivating pulse duration. These data indicate that G protein-inhibited channels inactivate slower than control channels and thus invalidate the intrinsic postulate of the prepulse method. However, we can't exclude the unexplored possibility that if channels inactivate preferentially from a partially-activated closed state, which may occur at $-30 \mathrm{mV}$, the action of $\mathrm{G}$ protein to favour a deeper closed-state could slow inactivation in spite of equal inactivation kinetics for both G protein bound and unbound channels.

To further illustrate the effect of $\mathbf{G}$ proteins on inactivation, the amplitude of control and DAMGO-inhibited currents were also followed for prepulses of various durations (Fig. 3). Fig. 3A illustrates a representative example of the evolution of current amplitudes over prepulse duration. As indicated, the control currents decrease much faster than DAMGOinhibited currents and an interesting convergence in current amplitude is observed by increasing the prepulse duration at $-30 \mathrm{mV}$. A quantification of this phenomenon indicates a far greater propensity of control currents to inactivate, whereas DAMGO-inhibited currents inactivate only mildly (Fig. 3B). For a prepulse duration of $30 \mathrm{sec}$, control currents inactivate by a factor of 6.25 -fold from $4.25 \pm 1.25 \mu \mathrm{A} / \mu \mathrm{F}$ to $0.68 \pm 0.30 \mu \mathrm{A} / \mu \mathrm{F}$ (84\% of inactivation). In contrast, for the same duration of inactivation, DAMGO-inhibited currents inactivate by a factor of 2.78 -fold from $1.64 \pm 0.52 \mu \mathrm{A} / \mu \mathrm{F}$ to $0.59 \pm 0.23 \mu \mathrm{A} / \mu \mathrm{F}$ (64\% of inactivation). The kinetics of inactivation was quantified for both control and DAMGO-inhibited currents (Fig. 3C). As shown, DAMGO-inhibited currents inactivate far slower than control currents. Data were fitted by a monoexponential decrease with time constants of $\tau=2.5 \mathrm{sec}$ (control currents) and $\tau=11.4 \mathrm{sec}$ (DAMGO-inhibited currents). Of note, the kinetics of DAMGOinhibited currents reflects the net kinetics of inactivation of a mixed population of channels (at 
least control and G protein bound channels) and it is expected that the kinetics of inactivation of $\mathrm{G}$ protein bound channels is still slower than that of DAMGO-inhibited currents. Taken together, these data indicate that $G$ protein-inhibited channels inactivate far slower than control channels.

At this stage, it is worth mentioning the possibility that a prepulse application to -30 $\mathrm{mV}$ could promote an intermediate closed state of the channel with greater affinity for $\mathrm{G} \beta \gamma$ complexes, thereby enhancing the proportion of $G$ protein bound channels available for channel opening. However nothing in the literature suggests that such a channel state may exist. On the contrary, it has been proposed that gating charge movements at potentials unable to produce channel openings may destabilize $G$ proteins from the channels, an event that would increase the proportion of control channels and thus rather produce the opposite result (case scenario of Fig. 2Bb).

Since our data indicate differences in inactivation kinetics between control and G protein-inhibited channels, we developed an alternative method to study direct G protein regulation at the quantitative level.

\subsection{Introduction of a novel method to study $G$ protein regulation of $C a_{v} 2.2 / \beta_{3}$ channels}

We present a step by step illustration of the method we developed using a representative example of a $\mathrm{Ca}_{v} 2.2$ / $\beta_{3}$ current inhibited by DAMGO application (Fig. 4). Control ( $\left.\mathrm{I}_{\text {Control }}\right)$ and DAMGO-inhibited ( $\mathrm{I}_{\text {DAMGO }}$ ) currents, currents recorded before and after $\mathrm{G}$ protein activation, respectively, were elicited by a test pulse at $10 \mathrm{mV}$ as shown in Fig. 4A. Subtracting $\mathrm{I}_{\mathrm{DAMGO}}$ from $\mathrm{I}_{\text {Control }}$ provides $\mathrm{I}_{\text {Lost }}$, the lost current following $\mathrm{G}$ protein activation (Fig. 4B, red trace). The time course of $\mathrm{I}_{\text {Lost }}$ is affected by both the recovery from $\mathrm{G}$ protein inhibition following channel activation (conversion of $G$ protein inhibited channels towards control channels) and by the inactivation process. We can't exclude that the time course of $\mathrm{I}_{\text {Lost }}$ is also affected by a third component, i.e. ion-conducting openings of presumably $\mathrm{G}$ protein-bound channels. In this study, the method we develop is based on the assumption that the channels do not undergo reluctant openings or that kinetic alterations introduced by these reluctant openings only mildly affect the data at the quantitative level, two assumptions that are difficult to test directly. At the start of the depolarization ( $\mathrm{t}$ $=0 \mathrm{~ms}$ ), there has been no recovery from $\mathrm{G}$ protein inhibition, no opening from $\mathrm{G}$ protein bound channels and inactivation has not taken place. Therefore, to estimate the maximal G protein inhibition, $I_{\text {Control }}$ and $I_{\text {Lost }}$ traces were extrapolated to $t=0$ ms. These current traces 
were best fitted with a single and a double exponential respectively (Fig. 4C, fits in red). A first parameter of $G$ protein regulation is extracted and termed $\mathrm{GI}_{\mathrm{t} 0}$ for $\mathrm{G}$ protein-induced current inhibition at the start of the depolarization $\left(\mathrm{GI}_{\mathrm{t} 0}=\mathrm{I}_{\mathrm{Lost}_{\mathrm{t} 0}} / \mathrm{I}_{\mathrm{Control}_{\mathrm{t} 0}} \times 100\right.$ when expressed as a percentage). Applying this percentage of $G$ protein inhibition to $I_{\text {Control }}$ results

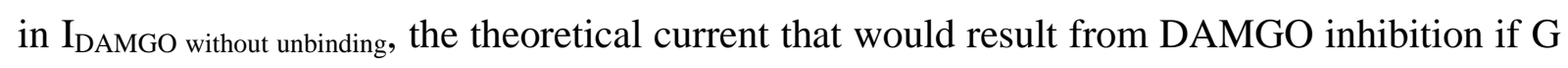
protein dissociation did not occur at all (Fig. 4D, red trace). Subtracting I

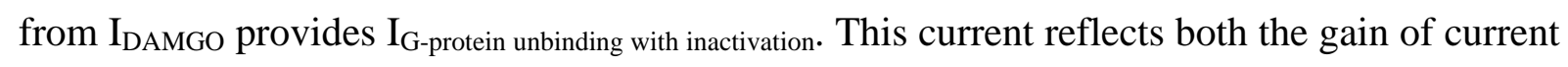
due to $G$ protein dissociation from the inhibited channels and inactivation of the gained current (Fig. 4E, red trace). The kinetics of the gain in current and inactivation are both apparent since the gain of current is affected by inactivation, whereas inactivation is altered by the gain in current. Since the gained current results from the conversion of G protein inhibited channels towards control channels, the real inactivation kinetics should be similar than control channels. In order to extract the net $\mathrm{G}$ protein dissociation component, $\mathrm{I}_{\mathrm{G} \text {-protein }}$ unbinding with inactivation is divided by a normalized curve that depicts the inactivation of control channels (control inactivation, dashed line, obtained by fitting $\mathrm{I}_{\text {Control }}$ by a single exponential)

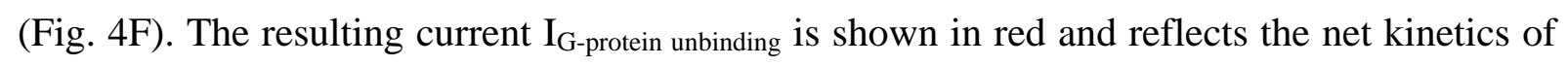

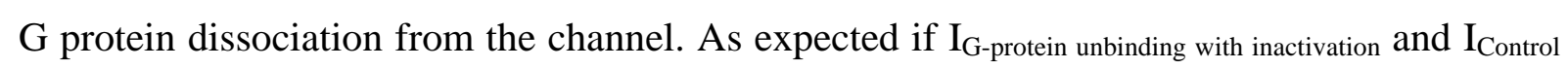

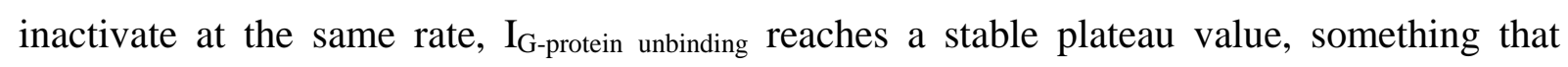
would not be observed if the real inactivation kinetics of these two currents were different. Fitting this trace by a decreasing single exponential provides the time constant $\tau$ of $\mathrm{G}$ protein dissociation (Fig. 4G, fit in red). This time constant represents the second critical parameter of $\mathrm{G}$ protein regulation of voltage-dependent calcium channel. This trace illustrate that the maximal G protein dissociation occurs well before the end of the $500 \mathrm{~ms}$ test pulse at $10 \mathrm{mV}$. Finally, to get an estimate of the total fraction of $G$ protein inhibited channels that recover from inhibition during the test pulse, we measured the percentage of current that had recovered from inhibition $(\mathrm{RI})$ such that: $\mathrm{RI}=100 \times\left(\left(\mathrm{I}_{\mathrm{DAMGO}}-\mathrm{I}_{\mathrm{DAMGO}}\right.\right.$ without unbinding $\left.) / \mathrm{I}_{\text {Control }}\right)$ at $\mathrm{t}=500 \mathrm{~ms}$ after the start of the depolarization, a time point where maximal recovery has occurred (Fig. 4H). RI represents the third important parameter that describes the calcium channel regulation by $\mathrm{G}$ proteins.

\subsection{Application of the method to a larger interval of potentials}

We first described $\mathrm{GI}_{\mathrm{t} 0}$ as a function of test potential (Fig. 5). Representative control and DAMGO-inhibited currents were shown for several test potentials $(-10,10$ and $30 \mathrm{mV})$ 
(Fig. 5Aa). $\mathrm{I}_{\text {Control }}$ and corresponding $\mathrm{I}_{\text {Lost }}$ are shown in Fig. 5Ab along with the fits extrapolated to $\mathrm{t}=0 \mathrm{~ms}$ (in red). The inhibition by $\mathrm{G}$ proteins was then represented as a function of test potential by either measuring peak current inhibition $\mathrm{GI}_{\text {Peak }}$ (Fig. 5B) or representing $\mathrm{GI}_{\mathrm{t} 0}$ (Fig. 5C). $\mathrm{GI}_{\mathrm{t} 0}$ remained statistically constant at all voltages since it reflects the $\mathrm{G}$ protein inhibition obtained at $-90 \mathrm{mV}$, the holding potential, before any dissociation can take place. On average, for $\mathrm{Ca}_{\mathrm{v}} 2.2$ / $\beta_{3}$ channels, $\mathrm{GI}_{\mathrm{t} 0}$ ranges between $63.2 \pm 6.6 \%(\mathrm{n}=10$, at $0 \mathrm{mV})$ to $58.8 \pm 6.0 \%(\mathrm{n}=10$, at $20 \mathrm{mV})$, a variation that is not statistically significant $(\mathrm{p}=$ $0.254)$, contrary to $\mathrm{GI}_{\text {Peak }}$ that varies from $57.1 \pm 7.2 \%(\mathrm{n}=10$, at $0 \mathrm{mV})$ to $22.5 \pm 6.4 \%(\mathrm{n}=$ 10 , at $40 \mathrm{mV}$ ), which is statistically different ( $\mathrm{p} \leq 0.001)$. Thus, when $\mathrm{G}$ protein inhibition is measured at the peak of the current ( $\left.\mathrm{GI}_{\text {Peak }}\right)$, the real inhibition can be largely underestimated. This was particularly the case at high voltages because of faster $G$ protein dissociation (Fig. 6). Therefore, $\mathrm{GI}_{\mathrm{t} 0}$ better reflects the real extent of $\mathrm{G}$ protein inhibition. Nevertheless, even

GI $_{\text {to }}$ may not be completely accurate since it relies on an extrapolation to time zero based on a fitting procedure that misses the first 5-10 ms of the trace.

Next, we quantified the $G$ protein dissociation parameters, $\tau$ and RI, as a function of test potential (Fig. 6). Control and DAMGO-inhibited traces are shown in Fig. 6Aa at different test potentials $\left(-10,10\right.$ and $30 \mathrm{mV}$ ). The corresponding $\mathrm{I}_{\mathrm{G} \text {-protein unbinding }}$ traces (Fig. $6 \mathrm{Ab}$ ) and traces for RI measurements (Fig. 6Ac) are shown according to the method detailed in Fig. 4. The time constants of $\mathrm{G}$ protein dissociation were plotted as a function of test potential (Fig. 6B, circle symbols). Fitting the values by a sigmoid curve indicates that the slowest time constant of dissociation is $73.3 \pm 12.0 \mathrm{~ms}$ for the lowest potentials, whereas the fastest time constant is $9.4 \pm 2.1 \mathrm{~ms}$ for the highest potentials with a half-maximal decrease in time constant of $8.6 \pm 1.8 \mathrm{mV}(\mathrm{n}=10)$. For comparison, we also plotted what the time constants of $\mathrm{G}$ protein dissociation would be using the prepulse method as described in Fig. 1 (Fig. 6B, triangle symbols). Differences were striking at the lowest voltages, whereas a slight convergence was observed at the highest potential values. For instance, at 0 and $10 \mathrm{mV}$, a difference of 4.0-fold was observed in the time constants of $\mathrm{G}$ protein dissociation between the two methods. At $40 \mathrm{mV}$, a 3.3-fold difference was still obvious suggesting that the prepulse method may underestimate the speediness of $G$ protein dissociation. Finally, RI values were represented as a function of test potential (Fig. 6C). Fitting these values with a single exponential rise to maximum provides a maximal extent of dissociation of $\mathrm{G}$ proteins of $61.6 \pm 3.4 \%(n=10)$. 


\section{Discussion}

Classically, the study of direct $G$ protein regulation is performed using prepulse applications. The technique, though widely recognized and easy to apply, makes the postulate that control and $G$ protein inhibited channels inactivate with the same rate. However, there are no data in the literature that tend to prove or disprove this assumption. This lack of information on the rate of inactivation of $G$ protein inhibited channels is due to technical difficulties. Here, we provide evidence that a conditioning pulse at $-\mathbf{3 0} \mathbf{~ m V}$ slows down the kinetics of $G$ protein modulated currents. The first straightforward explanation would be that $G$ proteins slow-down inactivation kinetics of $G$ protein-bound channels. However, two alternative explanations can be put forward: 1- the conditioning pulse at $30 \mathrm{mV}$ may favour a state of the channel that increases its affinity for activated G proteins, thereby increasing the proportion of $G$ protein-regulated channels. However, this explanation would be contradictory with reports mentioning that pre-activated states of the channel favour $G$ protein dissociation. 2- G proteins may favour a deeper closed state of the channel at $-30 \mathrm{mV}$, rendering activation and inactivation slower, although there is no experimental evidence for such a mechanism. Assuming that G protein-bound channels indeed inactivate slower than control channels at $-30 \mathrm{mV}$, it would be interesting to study how these G protein-bound channels behave at higher membrane potentials where the interesting information lie with regard to $G$ protein regulation. This is unfortunately difficult to test experimentally since G proteins dissociate upon channel opening. A slowing of channel inactivation by $\mathbf{G}$ proteins enters into a scientific logic that has already been observed on other occasions. The membrane-anchored calcium channel palmytoylated $\beta_{2 a}$ subunit is known to slow-down inactivation kinetics by the intermediate of the I-II loop (Restituito et al., 2000) which is a sensitive locus for the control of channel inactivation (Stotz et al., 2004). G proteins are known to bind to the cytoplasmic III loop of calcium channels as well (De Waard et al., 1997; Herlitze et al., 1997; Zamponi et al., 1997) and, depending of the $G \gamma$ subunit isoform, many $G$ proteins are also membrane linked by farnesyl or geranylgeranyl lipid moieties (Jones et al., 2004). The contribution of the I-II loop in G protein-induced current inhibition has been contested (De Waard et al., 2005; Zhang et al., 1996). However, it should be observed here that, if the I-II loop contributes in fact to a $G$ protein mediated slowing of inactivation kinetics for $G$ proteinbound channels, then this effect would have remained largely unnoticed. 
In this context of uncertainties regarding the contribution of $G$ protein to inactivation kinetics, we have developed an alternative descriptive method for the analysis of regulation of voltage-dependent calcium channel by $G$ proteins. This method does not require that $G$ protein-inhibited channels inactivate with the same rate than control channels. However, like any other method, it is not model-independent and does not necessarily provide accurate parameters for all conceivable mechanisms of coupling between activation and inactivation. The method described herein is not based on the use of prepulse potentials that are often applied along with an interpulse potential, thereby providing an incentive for $\mathrm{G}$ protein rebinding onto the channel. It simply requires current traces before and after $G$ proteins activation, simplifying the electrophysiological protocol. A limitation of the method however is that it is limited to a range of potentials where currents can be measured flowing through the channel. The method gives access to three major parameters of $G$ protein regulation: $\mathrm{GI}_{\mathrm{t} 0}$, the initial extent of $\mathrm{G}$ protein inhibition that reflects the "ON" effect of regulation, and, $\tau$, the time constant of $\mathrm{G}$ protein dissociation from the channel, and RI, the percentage of recovery from inhibition, that both characterize the "OFF" effects of the regulation. Several predictions were met when applying this method. First, $\mathrm{GI}_{\mathrm{t} 0}$ remains constant with increasing test potentials, an observation not made when measuring peak currents. Second, the rate of G protein dissociation speeds up with increasing depolarization values within an interval of potentials known to increase the opening probability. Third, the extent of dissociation increases with test potential values. The observation we made with this novel method are of course qualitatively similar to what can be observed with the prepulse method. However, we note some quantitative differences that may have important consequences. One such consequence is that when a pulse is applied at $10 \mathrm{mV}$, a significant fraction of the $G$ proteins have already dissociated from the channels at the peak of the current. Indeed, with a time constant of about $30 \mathrm{~ms}$ at $10 \mathrm{mV}$, two thirds of the Groteins that have the capability to dissociate have already done so by that time. DAMGO-inhibited currents had a peak well beyond these first $30 \mathrm{~ms}$ at $10 \mathrm{mV}$ (Fig. 2), indicating the extent of the under-evaluation of $\mathrm{G}$ protein parameters. In these conditions, a prepulse application would not provide the desired results and the extent of facilitation could well be underevaluated or even remain unnoticed. This is obvious from the data presented in Fig. 5B,C where $G$ protein inhibition values are largely under-estimated when measuring at the peak ( $\left(\mathrm{I}_{\text {Peak }}\right)$ of the $\mathrm{G}$ protein-inhibited currents. 
In summary, we present a novel method for analysing $G$ protein regulation of voltagedependent calcium channels. This method provides similar qualitative information compared to the prepulse method. It may therefore be used as an interesting alternative for an estimate of quantitative parameters of $\mathbf{G}$ protein regulation. The method has been developed here on expressed channels in Xenopus oocytes, and further investigations will be required to confirm its validity on native channels from mammalian cells.

\section{Acknowledgements}

We acknowledge financial support from Inserm and the French Ministry of Research and Technology. The clone coding for rat $\mu$-opioid receptor was kindly provided by Dr. Pierre Charnet (CNRS, Montpellier, France).

\section{Footnotes}

The following abbreviations have been used. GPCR: G protein coupled receptors; DAMGO: D-Ala ${ }^{2}, M_{e}-P^{4}{ }^{4}$ glycinol $^{5}$ )-enkephalin. 


\section{References}

Bean BP. Neurotransmitter inhibition of neuronal calcium currents by changes in channel voltage dependence. Nature 1989;340:153-6.

Boland LM, Bean BP. Modulation of N-type calcium channels in bullfrog sympathetic neurons by luteinizing hormone-releasing hormone: kinetics and voltage dependence. $\mathrm{J}$ Neurosci 1993;13:516-33.

Bourinet E, Soong TW, Stea A, Snutch TP. Determinants of the G protein-dependent opioid modulation of neuronal calcium channels. Proc Natl Acad Sci U S A 1996;93:1486-91.

Carabelli V, Lovallo M, Magnelli V, Zucker H, Carbone E. Voltage-dependent modulation of single N-Type $\mathrm{Ca}^{2+}$ channel kinetics by receptor agonists in IMR32 cells. Biophys J 1996;70:2144-54.

Colecraft HM, Patil PG, Yue DT. Differential occurrence of reluctant openings in Gprotein-inhibited N- and P/Q-type calcium channels. J Gen Physiol 2000;115:175-92.

De Waard M, Hering J, Weiss N, Feltz A. How do G proteins directly control neuronal $\mathrm{Ca}^{2+}$ channel function? Trends Pharmacol Sci 2005;26:427-36.

De Waard M, Liu H, Walker D, Scott VE, Gurnett CA, Campbell KP. Direct binding of Gprotein betagamma complex to voltage-dependent calcium channels. Nature 1997;385:44650.

Dunlap K, Fischbach GD. Neurotransmitters decrease the calcium conductance activated by depolarization of embryonic chick sensory neurones. J Physiol 1981;317:519-35.

Elmslie KS, Jones SW. Concentration dependence of neurotransmitter effects on calcium current kinetics in frog sympathetic neurones. J Physiol 1994;481 ( Pt 1):35-46.

Eppig JJ, Dumont JN. Defined nutrient medium for the in vitro maintenance of Xenopus laevis oocytes. In Vitro 1976;12:418-27.

Herlitze S, Hockerman GH, Scheuer T, Catterall WA. Molecular determinants of inactivation and $G$ protein modulation in the intracellular loop connecting domains I and II of the calcium channel alpha1A subunit. Proc Natl Acad Sci USA 1997;94:1512-6.

Ikeda SR. Double-pulse calcium channel current facilitation in adult rat sympathetic neurones. J Physiol 1991;439:181-214.

Jones MB, Siderovski DP, Hooks SB. The G $\beta \gamma$ dimer as a novel source of selectivity in Gprotein signaling: GGL-ing at convention. Mol Interv 2004;4:200-14.

Jones SW, Elmslie KS. Transmitter modulation of neuronal calcium channels. J Membr Biol 1997;155:1-10.

Lee HK, Elmslie KS. Reluctant gating of single N-type calcium channels during neurotransmitter-induced inhibition in bullfrog sympathetic neurons. $J$ Neurosci 2000;20:3115-28. 
Lipscombe D, Kongsamut S, Tsien RW. Alpha-adrenergic inhibition of sympathetic neurotransmitter release mediated by modulation of N-type calcium-channel gating. Nature 1989;340:639-42.

Marchetti C, Carbone E, Lux HD. Effects of dopamine and noradrenaline on Ca channels of cultured sensory and sympathetic neurons of chick. Pflügers Arch 1986;406:104-11.

Patil PG, de Leon M, Reed RR, Dubel S, Snutch TP, Yue DT. Elementary events underlying voltage-dependent G-protein inhibition of N-type calcium channels. Biophys J 1996;71:250921.

$\mathrm{Qu}$ Z, Hartzell HC. Functional geometry of the permeation pathway of $\mathrm{Ca}^{2+}$-activated $\mathrm{Cl}^{-}$ channels inferred from analysis of voltage-dependent block. J Biol Chem 2001;276:18423-9.

Restituito S, Cens T, Barrere C, Geib S, Galas S, De Waard M, Charnet P. The beta2a subunit is a molecular groom for the $\mathrm{Ca}^{2+}$ channel inactivation gate. J Neurosci 2000;20:9046-52.

Roche JP, Anantharam V, Treistman SN. Abolition of G protein inhibition of alpha 1A and alpha 1B calcium channels by co-expression of the beta 3 subunit. FEBS Lett 1995;371:43-6.

Roche JP, Treistman SN. The $\mathrm{Ca}^{2+}$ channel beta3 subunit differentially modulates G-protein sensitivity of alpha1A and alpha1B $\mathrm{Ca}^{2+}$ channels. J Neurosci 1998;18:878-86.

Scott RH, Dolphin AC. Voltage-dependent modulation of rat sensory neurone calcium channel currents by $\mathrm{G}$ protein activation: effect of a dihydropyridine antagonist. $\mathrm{Br} \mathrm{J}$ Pharmacol 1990;99:629-30.

Stephens GJ, Brice NL, Berrow NS, Dolphin AC. Facilitation of rabbit alpha1B calcium channels: involvement of endogenous Gbetagamma subunits. J Physiol 1998;509 ( Pt 1):1527.

Stotz SC, Jarvis SE, Zamponi GW. Functional roles of cytoplasmic loops and pore lining transmembrane helices in the voltage-dependent inactivation of HVA calcium channels. J Physiol 2004;554:263-73.

Weiss N, Arnoult C, Feltz A, De Waard M. Contribution of the kinetics of G protein dissociation to the characteristic modifications of N-type channel activity. Submitted.

Wu LG, Saggau P. Presynaptic inhibition of elicited neurotransmitter release. Trends Neurosci 1997;20:204-12.

Zamponi GW, Bourinet E, Nelson D, Nargeot J, Snutch TP. Crosstalk between G proteins and protein kinase C mediated by the calcium channel alpha1 subunit. Nature 1997;385:442-6.

Zhang JF, Ellinor PT, Aldrich RW, Tsien RW. Multiple structural elements in voltagedependent $\mathrm{Ca}^{2+}$ channels support their inhibition by G proteins. Neuron 1996;17:991-1003. 


\section{Figures legends}

Fig. 1. Analysis of $G$ protein regulation by the prepulse method. (A) Experimental protocol to measure prepulse-induced facilitation of $\mathrm{Ca}_{\mathrm{v}} 2.2 / \beta_{3}$ currents as a function of prepulse duration and voltage for control and DAMGO-inhibited currents. P1, pulse without prepulse PP, and P2, pulse following a PP application. (B) Representative current traces for control and DAMGO conditions elicited by $500 \mathrm{~ms} \mathrm{P} 1$ at $10 \mathrm{mV}$ and $500 \mathrm{~ms}$ P2 at $10 \mathrm{mV}$ following PP at $70 \mathrm{mV}$ of variable durations. (C) P2/P1 peak current amplitude ratio for control (open circles, $\mathrm{n}=7$ ) and DAMGO (filled circles, $\mathrm{n}=7$ ) conditions. (D) Normalized prepulse facilitation (P2/P1 $\left.1_{\text {DAMGO }} / \mathrm{P} 2 / \mathrm{P} 1_{\text {control }}\right)$ to eliminate prepulse-induced inactivation component. Results were fitted by a single exponential rise to maximum yielding an average time constant $\tau=$ $19.6 \pm 2.6 \mathrm{~ms}$ and a maximal facilitation of $1.6 \pm 0.2$ fold.

Fig. 2. Experimental evidence that $G$ proteins alter the inactivation time course of $\mathrm{Ca}_{\mathrm{v}} 2.2 / \beta_{3}$ channels. (A) $a$, Representative current traces obtained at $20 \mathrm{mV}$ for control (black trace) and DAMGO (red trace) conditions. Symbols under traces indicate the peaks of the currents. $b$, Average DAMGO inhibition at peak currents $(\mathrm{n}=7) . c$, Average shift of the current time to peak induced by DAMGO application $(\mathrm{n}=7)$. $d$, DAMGO-induced slowing factor of inactivation kinetics when fitted by a single exponential decay $(n=7)$. (B) Simulated evolution of channel population fraction (ratio between control channels and G proteininhibited channels that are not yet inactivated) as a function of time at an inactivating prepulse at $-30 \mathrm{mV}$ and resulting consequences on DAMGO-inhibited current kinetics. $a$, First case scenario where both channel populations inactivate with the same rate. The ratio of channel populations able to undergo activation before and during the inactivating prepulse remains constant. The kinetics of DAMGO-inhibited current remains unchanged at any given time $t$ of the inactivating prepulse. $b$, Second case scenario where $\mathrm{G}$ protein inhibited channels inactivate faster than control channels. The ratio between these two channel populations becomes progressively in favour of control channels. The resulting DAMGO-inhibited current kinetics gets faster. $c$, Third case scenario where $G$ protein inhibited channels inactivate slower than control channels. The ratio between these two channel populations becomes progressively in favour of $G$ protein-inhibited channels. The resulting DAMGO-inhibited current kinetics becomes slower. The traces shown are from a representative experimental control traces, whereas the DAMGO-inhibited currents were simulated by the following equation $\mathrm{I}_{\mathrm{DAMGO}}=\left[\mathrm{I}_{\text {Control }} \times(100-\mathrm{GI}) / 100\right]+\left[\mathrm{I}_{\text {Control }} \times(\mathrm{GI} / 100) \times(1-\exp (-(1 / \tau) \times \mathrm{t})) \times(\mathrm{RI} / 100)\right]$ 
(Weiss et al., submitted) where GI is the percentage of G protein inhibition at the peak of the current, $\tau$ the time constant of recovery from $\mathrm{G}$ protein inhibition at $20 \mathrm{mV}$ ( $\tau=52 \mathrm{~ms}$ in this example), and RI the percentage of relief from $\mathrm{G}$ protein inhibition at $20 \mathrm{mV}(\mathrm{RI}=42 \%$ in this example). Only GI values were varied (60\% in $a, 20 \%$ in $b$, and $80 \%$ in $c$ ). (C) $a$, Representative current traces elicited at $20 \mathrm{mV}$ for control condition (black trace with fast kinetics) and DAMGO condition without (red trace) or following an inactivating prepulse at $30 \mathrm{mV}$ of variable duration (coloured traces). The current traces were normalized at their peak amplitude. Note the slowing of activation and inactivation kinetics induced by DAMGO (black arrow) and then by the inactivating prepulse (red arrow). $b$, Average shift of the current time to peak of DAMGO-inhibited currents as a function of the $-30 \mathrm{mV}$ inactivating prepulse duration $(\mathrm{n}=7)$. $c$, Evolution of the time constant of current inactivation for DAMGOinhibited currents as a function of the $-30 \mathrm{mV}$ inactivating prepulse duration $(\mathrm{n}=7)$.

Fig. 3. G protein-inhibited $\mathrm{Ca}_{\mathrm{v}} 2.2$ / $\beta_{3}$ channels inactivate slower than control channels. (A) Representative traces of control and DAMGO-inhibited currents before (a) and after 2.5 sec (b) and $30 \mathrm{sec}(c)$ application of an inactivating prepulse at $-30 \mathrm{mV}$. The circles indicate the time to peak of the currents. (B) Evolution of average current densities for control (black bars, $\mathrm{n}=7$ ) and DAMGO (open bars, $\mathrm{n}=7$ ) conditions as a function of inactivating prepulse duration at $-30 \mathrm{mV}$. Currents measured at peak amplitudes. Statistical paired $t$-test with NS (non significant), * ( $\mathrm{p} \leq 0.05), * *(\mathrm{p} \leq 0.01)$, and *** ( $\mathrm{p} \leq 0.001)$. (C) Average normalized current amplitudes for control (black circles, $n=7$ ) and DAMGO (open circles, $n=7$ ) conditions as a function of inactivating prepulse duration at $-30 \mathrm{mV}$. Data were fitted with monoexponential equations.

Fig. 4. Illustration of an alternative method for the analysis of $\mathrm{Ca}_{\mathrm{v}} 2.2$ / $\beta_{3}$ channel regulation by $G$ proteins. (A) Representative current traces elicited at $10 \mathrm{mV}$ for control ( $\mathrm{I}_{\text {Control }}$ ) and DAMGO ( $\mathrm{I}_{\text {DAMGO }}$ ) conditions. (B) Lost current ( $\mathrm{I}_{\text {Lost }}$, red trace) under $\mathrm{G}$ proteins activation obtained by subtracting $\mathrm{I}_{\mathrm{DAMGO}}$ from $\mathrm{I}_{\text {Control}}$. The dashed line represents the zero current level and the arrow the start of the depolarization. (C) $\mathrm{I}_{\text {Control }}$ and $\mathrm{I}_{\mathrm{Lost}}$ were extrapolated to $\mathrm{t}=0 \mathrm{~ms}$ (start of the depolarization) by fitting traces (red dashed lines) with a single and double exponential respectively in order to determine the maximal extent of $G$ protein inhibition $\left(\mathrm{GI}_{\mathrm{t} 0}\right.$ ). (D) Estimate of the fraction of control currents that is present in $\mathrm{I}_{\text {DAMGO }}$ ( $\mathrm{I}_{\text {DAMGO without }}$ unbinding, red trace) and that is due to a population of control channels. It is obtained by the 
following equation: $I_{\text {Control }} \times\left(1-\mathrm{GI}_{\mathrm{t} 0}\right)$. $(\mathrm{E})$ The fraction of $\mathrm{I}_{\mathrm{DAMGO}}$ current that recovers from $\mathrm{G}$ protein inhibition ( $\mathrm{G}$ protein inhibited channel population) is shown in red ( $\mathrm{I}_{\mathrm{G}-\text { protein unbinding with }}$

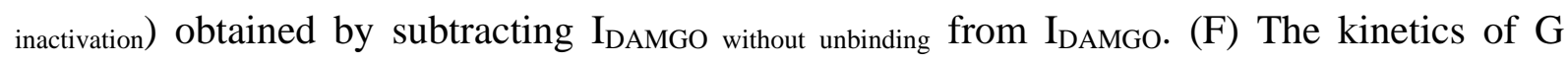

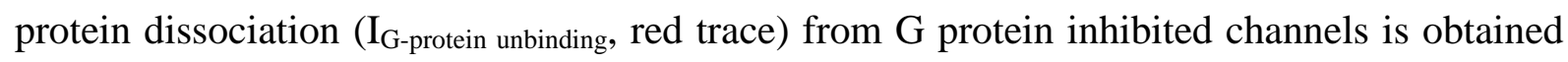
by dividing $\mathrm{I}_{\mathrm{G}-p r o t e i n}$ unbinding with inactivation by the normalized control inactivation component (dashed line obtain by fitting $\mathrm{I}_{\text {Control }}$ with a single exponential). (G) Fit of $\mathrm{I}_{\mathrm{G} \text {-protein unbinding, }}$ dashed red line) by a single exponential decrease provides the time constant $\tau$ of G protein dissociation from the channel. $(\mathrm{H})$ Measure of the percentage of recovery from $\mathrm{G}$ protein inhibition (RI) at the end of $500 \mathrm{~ms}$ pulse at $10 \mathrm{mV}$ by $\mathrm{RI}=\left(\mathrm{I}_{\text {DAMGO }}-\mathrm{I}_{\text {DAMGO without unbinding }}\right) /$ $\mathrm{I}_{\text {Control }} \times 100$.

Fig. 5. Evolution of the extent of $\mathrm{G}$ protein inhibition as a function of test potential. (A) $a$, Representative current traces for control and DAMGO conditions elicited at -10, 10 and 30 $\mathrm{mV}$. Symbols under traces represent the peak of the currents. $b$, Corresponding $\mathrm{I}_{\text {Lost }}$ traces fitted with a double exponential (dashed red trace) allowing $\mathrm{GI}_{\mathrm{t} 0}$ measurements. Black dashed line represents the zero current level and the arrow points to the start of the depolarization $(\mathrm{t}=$ $0 \mathrm{~ms}$ ). (B) Evolution of $\mathrm{G}$ protein inhibition extent as a function of test potential when measured at the peak of the currents $\left(\mathrm{GI}_{\text {Peak }}\right)(\mathrm{n}=10)$. (C) Evolution of $\mathrm{G}$ protein inhibition extent at the start of the depolarisation $\left(\mathrm{GI}_{\mathrm{t} 0}\right)$ as a function of test potential $(\mathrm{n}=10)$.

Fig. 6. Evolution of $G$ protein dissociation parameters as a function of test potential. (A) $a$, Representative current traces for control and DAMGO conditions elicited at -10, 10 and 30

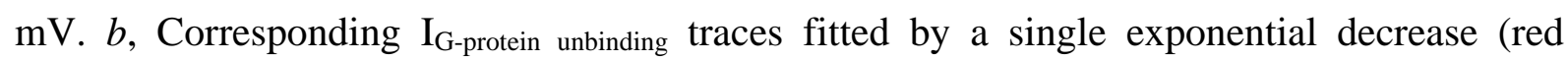
dashed line). $c$, Corresponding current traces required to measure RI value as described in Fig. $3 \mathrm{H}$. Black dashed line represents the zero current level and the arrow points to the start of the depolarization ( $\mathrm{t}=0 \mathrm{~ms}$ ). (B) Logarithmic representation of time constants $\tau$ of $\mathrm{G}$ protein dissociation as a function of test potential obtained by the classical prepulse method (triangle symbol) or by fitting $\mathrm{I}_{\mathrm{G}-p r o t e i n}$ unbinding $(\mathrm{Ab})$ with a single exponential decrease (circle symbol). Values were fitted by a sigmoid curve yielding a half-maximal increase in the time constant at $-2.4 \pm 1.0 \mathrm{mV}(\mathrm{n}=22)$ for the prepulse method and $8.6 \pm 1.8 \mathrm{mV}(\mathrm{n}=10) \mathrm{mV}$ for this novel method. (C) Extent of G protein dissociation (RI) as a function of test potential. Values were fitted by a single exponential rise providing the maximum extent of recovery of $61.6 \pm 3.4 \%$ $(n=10)$. 
